\title{
TRACING THE CONTACTS OF MALE PATIENTS WITH ACUTE GONORRHOEA*
}

\author{
BY \\ M. C. HAWORTH (Almoner) and C. S. NICOL \\ Special Treatment Centre, St. Bartholomew's Hospital, London
}

Special printed contact slips with counterfoils, in book form, have been in use at the Special Treatment Centre at St. Bartholomew's Hospital since April, 1951. A review of the results of contact tracing by this method may be of some interest.

The group chosen for the review comprised 190 male patients with acute gonorrhoea diagnosed in the period April 3, 1951, to August 3, 1953. Only 149 of these patients were actually given one or more contact slips, as this was not done in cases where tracing would be completely impracticable ; for instance when a patient insisted that he would not recognise the contact, or when she was resident abroad. Altogether 34 female contacts were traced and examined (thirty at the Special Treatment Centre, and four at other centres), and 29 were diagnosed as having acute gonorrhoea (26 at the ${ }^{*}$ Special Treatment Centre and three at other centres) (see Table). Of these 29 contacts, eighteen were wives, and five the regular consorts of the original patients, the remaining six being friends or casual contacts. Only one patient brought both his wife and his extra-marital contact for examination ; the latter had acute gonorrhoea, and the former showed no evidence of the disease.

TABLE

\begin{tabular}{llll|r}
\hline Total Males with Gonorrhoea & $\ldots$ & $\ldots$ & $\ldots$ & 190 \\
Males given Contact Slips .. & $\ldots$ & $\ldots$ & $\ldots$ & $149(78 \%)$ \\
Female Contacts traced $\ldots$ & $\ldots$ & $\ldots$ & $\ldots$ & $34(18 \%)$ \\
Females found to have Acute Gonorrhoea & $\ldots$ & $29(15 \%)$ \\
\hline
\end{tabular}

The contact slip was normally given to the patient by the doctor or by the almoner at the first attendance. Every male patient with acute gonorrhoea was interviewed by the almoner, and the question of contact tracing was discussed in detail. When a contact slip was given, the almoner completed the counterfoil with details of the diagnosis, the patient's marital status, and the relationship of the contact

* Received for publication November 13, 1953 to be traced. The contact's number and diagnosis were added in due course if she did in fact attend, and the books of completed counterfoils were kept as a permanent record.

It seems essential for the detailed interview to take place at the patient's first attendance. If the opportunity for discussion, however unfruitful, is missed at this juncture, it may be lost altogether. It was found that some of the patients in the group were unreliable, and tended to default once they had been treated. Some had no permanent address, and others gave false or temporary addresses, from which follow-up letters were subsequently returned by the Post Office.

Nearly all the male patients were willing to discuss the question of contact tracing, and only an occasional patient was openly uncooperative. A frank refusal to ask a known contact to attend was very rare, and reassurances and persuasion were generally effective in ensuring at least that a genuine attempt at arranging the attendance would be made. In the few cases where all attempts at persuasion failed, and the patient would neither ask the known contact to attend, nor give permission for a visit to be made by the almoner, the underlying problem proved in each case to be a matrimonial one. In three cases there was a history of repeated extra-marital risks, and the patients insisted that if their wives were examined their marriages would be broken up. The risk and danger to the wife's health were fully explained but the patients remained completely uncooperative. In two other cases where the wife came of her own accord to be examined, it was found that the history given by the husband was inaccurate, and was intended as a safeguard against any attempt at contact tracing. One man registered as single, admitting only two untraceable casual contacts. His wife found out by chance about his attendances at the Special Treatment Centre, and came for an 
examination, which proved that she too had acute gonorrhoea. There was a long history of matrimonial difficulties and divorce proceedings had already been instituted. Another male patient claimed to have been separated from his wife for over a year. She too came voluntarily to be examined, having found out by chance about his attendance. She was not infected, but from the history she gave, she and her husband had never in fact been separated, so that she should have been examined earlier as a contact.

The contacts of the majority of the patients were entirely casual, which meant that tracing was often quite impracticable. The patient had often met the contact once only, at a public house, dance hall, or cinema. He rarely knew her surname, or had any idea where she lived, and the only chance of finding her again was for him to revisit the place of the original meeting. The information available was so vague and inconclusive that referral with the patient's consent to the contact's local Medical Officer of Health for tracing was very rarely indicated. It was only attempted in two cases during the period under review. In one case the attempt failed completely. In the other, the named contact, who was interviewed by a local Health Visitor, denied the patient's allegations altogether, and refused to be examined at the local centre as suggested.

Summary

(1) The results of contact tracing in this group show clearly that it is most often successful where the contact is the patient's wife or regular consort. Of the 29 contacts found to have acute gonorrhoea, 23 were the wives or regular consorts of the original patients.

(2) The hard core of the problem is the entirely casual contact, who is almost always untraceable, and this accounts for the disappointingly high proportion of failures. Despite these failures, it is still felt worthwhile to continue the system of detailed interviewing and individual follow-up to ensure that at least an attempt at tracing is made in the case of every known contact of a male patient with acute gonorrhoea.

(3) Where time and staffing permit, the almoner should interview every male patient with acute gonorrhoea at the first attendance, and arrange subsequent interviews until the contact has actually attended, or until every reasonable attempt has proved unsuccessful.

(4) The use of a printed book of contact slips with counterfoils assists contact tracing and facilitates accurate recording and follow-up. 